This PDF is a selection from a published volume from the National Bureau of Economic Research

Volume Title: Innovation Policy and the Economy, Volume 4

Volume Author/Editor: Adam B. Jaffe, Josh Lerner and Scott Stern, editors

Volume Publisher: The MIT Press

Volume ISBN: 0-262-10104-1

Volume URL: http://www.nber.org/books/jaff04-1

Conference Date: April 15, 2003

Publication Date: February 2004

Title: Technology Policy for Energy and the Environment

Author: Adam B. Jaffe, Richard G. Newell, Robert N. Stavins

URL: http://www.nber.org/chapters/c10799 


\section{Technology Policy for Energy and the Environment}

Adam B. Jaffe, Brandeis University and NBER

Richard G. Newell, Resources for the Future

Robert N. Stavins, Harvard University and Resources for the Future

\section{Executive Summary}

We analyze the implications of the interaction of market failures associated with pollution and the environment, and market failures associated with the development and diffusion of new technology. These combined market failures imply a strong prima facie case for public policy intervention to foster environmentally beneficial technology. Both theory and empirical evidence suggest that the rate and direction of technological advance is influenced by incentives from the market and from regulation. Environmental policy based on incentive-based approaches is more likely to foster cost-effective technology innovation and diffusion than policy based on command and control approaches. In addition, society's investments in the development and diffusion of new environmentally beneficial technologies is very likely to be less than socially desirable in the presence of weak or nonexistent environmental policies that would otherwise foster such technology. Positive knowledge, adoption spillovers, and information problems further weaken innovation incentives. While environmental technology policy is fraught with difficulties, a long-term view suggests a strategy of experimenting with different policy approaches and systematically evaluating their success.

\section{Introduction}

In the last decade, discussions of energy and environmental policy have become increasingly permeated by issues related to technological change. Technological change is important to environmental policy for three broad reasons. First, the environmental impact of social and economic activity is profoundly affected by the rate and direction of technological change. New technologies may create or facilitate increased pollution, or may mitigate or replace existing polluting activities. Also, because many environmental problems and policy responses thereto are evaluated over time horizons of decades or centuries, the cumula- 
tive impact of technological changes is likely to be large. Indeed, uncertainty about the future rate and direction of technological change is often the single greatest limitation to our ability to forecast future environmental conditions (Weyant 1993, Energy Modeling Forum 1996).

Second, environmental policy interventions themselves create new constraints and incentives that affect the process of technological change. These induced effects of environmental policy on technology may have substantial implications for the normative analysis of policy decisions. They may have quantitatively important consequences in the context of cost-benefit or cost-effectiveness analyses of such policies. They may also have broader implications for welfare analyses because the process of technological change is characterized by externalities and market failures, with important welfare consequences beyond those associated with environmental issues.

Finally, the seeming intractability of some energy and environmental problems today, such as global climate change, combined with the long time frame over which their ultimate consequences will play out, make the development and deployment of new technologies attractive to many as a major or perhaps primary policy response to those problems. That is, policies whose direct purpose is generating technology may be as or more important for helping the environment, in the long run, as the rules and regulations we normally think of as environmental policies.

This paper provides background for consideration of these issues. We begin by discussing the key analytic issues that permeate policy discussions occurring at the nexus between technology and environmental policy. Section III then addresses the design of environmental policy to incorporate and exploit its impacts on technology. Section IV discusses the possibilities for policies designed to operate directly on technology to improve our ability to cope with environmental problems. We offer concluding observations in Section V.

\section{Important Analytical Issues}

\section{Multiple Market Failures}

\section{Environmental Economics 101}

Environmental Externalities Economic analysis of environmental policy is based on the idea that the potentially harmful consequences of economic activities on the environment constitute an externality. An 
externality is an economically significant effect of an activity, the consequences of which are borne (at least in part) by a party or parties other than the party who controls the externality-producing activity. A factory that pollutes the air, water, or land imposes a cost on society. The firm that owns the factory has an economic incentive to use only as much labor or steel as it can productively employ because those inputs are costly to the firm. In simpler terms, the cost to society of having some of its labor and steel used up in a given factory is internalized by the firm because it has to pay for those inputs. But the firm does not (in the absence of appropriate environmental policy intervention) have an economic incentive to minimize the external costs of pollution.

Normative economics teaches that externalities are an example of market failure, meaning that in the presence of externalities, Adam Smith's "invisible hand" may not operate to produce outcomes that are socially desirable. While the details and refinements are important, all environmental policies, at their core, are designed to deal with this externality problem, either by internalizing environmental costs so that polluters will make efficient decisions regarding their consumption of environmental inputs, or else by imposing from the outside a level of environmental pollution that policy makers believe to be more efficient than that otherwise chosen by firms.

In the short run, efficient environmental policy requires comparing the marginal cost of reducing pollution with the marginal benefit of a cleaner environment. All other factors being equal, emissions of pollutants that are very harmful should be greatly restricted because doing so produces large marginal benefits. All other factors being equal, emissions of pollutants that are very costly to eliminate should be tolerated because the marginal cost of reducing them is high. This cost could be in the form of decreased output of desired products (e.g., a scrubber on an electric power plant reduces its electricity production from a given quantity of fuel), increased use of other variable inputs (e.g., eliminating certain gases from the waste stream in a smokestack may require more fuel to be burned), purchase of specialized pollution-control equipment (e.g., catalytic converters on automobiles), or substitution of inferior or more expensive products or production methods to avoid pollution-causing products or methods (e.g., less effective pesticides coming into use when DDT was banned).

Analytically, technology enters the picture by changing the terms of the trade-off between the marginal cost of pollution control and its 
marginal social benefit. In particular, new technology-such as new pollution-control equipment, or new substitutes for environmentally harmful products-typically reduces the marginal cost of achieving any given level of pollution reduction. This means that a specified level of environmental cleanup can be reduced at lower total cost to society, and it also means that it will typically be efficient to choose a lower level of pollution than would be efficient if cleanup were more expensive. Thus, in this simple static picture, improved technology can be good for both the firms that must meet environmental mandates and for the environment itself.

\section{Economics of Technology 101}

If new technology makes it less expensive over time to reduce pollution, then it is obviously a good thing. If this were the end of the analytic story, then the only effect would be to convert the analysis of environmental policy from a static cost/benefit trade-off to a dynamic one. Policies to reduce pollution have two effects, however: they reduce pollution today, and they also typically change the incentives that firms face with regard to investing resources in developing new technology. In particular, when firms face an incentive to reduce their emissions, this simultaneously creates an incentive for them to find ways to reduce pollution at lower cost. The fact that the development of such technology will, over time, change the pollution benefit/cost calculus means that choosing efficient environmental policy requires an analysis of this dynamic interaction.

Of course, new technology is not itself free. To get to the point where pollution is being reduced or some other benefit is realized, two things must happen, both of which require the investment of resources. The first step, which we will call innovation, involves scientific or engineering research to establish a new technical idea and the development necessary to embody that idea in a commercial product or process. ${ }^{1}$ The second step is adoption or diffusion, the process by which a new product or process gradually replaces older technology in multiple firms and applications. Adoption is also costly because firms have to learn about new technology, purchase new equipment, and frequently adapt it to their particular circumstances.

This leads us to the question of whether we can expect the "invisible hand" to choose the right level of investment in both innovation and diffusion of new technology. It turns out that, independent of the 
externality associated with pollution, innovation and diffusion are both characterized by externalities, as well as other market failures.

Knowledge Externalities In the case of pollution, the problem is that a polluter imposes costs on others and hence has an inadequate incentive, from a social perspective, to reduce those costs. With respect to technology, the problem is the reverse. A firm that develops or implements a new technology typically creates benefits for others and hence has an inadequate incentive to increase those benefits by investing in technology. Pollution is a negative externality, and so the "invisible hand" allows too much of it. Technology creates positive externalities, and so the "invisible hand" produces too little of it."

With respect to innovation, the positive externality derives from the public good nature of new knowledge. If I build a better mousetrap, and once the world beats a path to my door, my competitors can see what I did and learn something from it. The process of competition will typically drive me to sell my new device at a price that captures only a portion of its full value, so that consumers also benefit from the new technology. While we have patents and other institutions that try to protect firms' investments in innovation, such protection is inherently imperfect. A successful innovator will capture some rewards, but those rewards will always be only a fraction-and sometimes a very small fraction-of the overall benefits to society of the innovation. Hence, innovation creates positive externalities in the form of knowledge spillovers for other firms, and spillovers of value or consumer surplus for the users of the new technology.

Adoption Externalities The environmental and knowledge externalities discussed above have been understood for a long time and have long been at the center of economic debates about technology policy. More recently, we have come to understand some additional market failures that operate in the adoption and diffusion of new technology. For several reasons, the cost or value of a new technology to one user may depend on how many other users have adopted the technology. In general, users will be better off the more other people use the same technology. This benefit associated with the overall scale of technology adoption is sometimes referred to as dynamic increasing returns.

Dynamic increasing returns can be generated by learning by using, learning by doing, or network externalities. While the image of the 
world beating a path to the door of the successful innovator is a compelling one, the diffusion of a new technology is typically gradual. It takes time for the many potential users to learn of the new technology, try it, adapt it to their circumstances, and become convinced of its superiority. An important mechanism in this learning process is the observation of the adoption of the new technology by others. If a neighbor or competitor tries something new and I see that it works, it becomes much safer and easier for me to try it. Hence, the adopter of a new technology creates a positive externality for others, in the form of the generation of information about the existence, characteristics, and success of the new technology. This phenomenon is often called learning by using.

The supply-side counterpart, learning by doing, describes how production costs tend to fall as manufacturers gain production experience. If this learning spills over to benefit other manufacturers, it can represent an additional adoption externality. Finally, network externalities exist if a product is technologically more valuable to an individual user as other users adopt a compatible product (for example, telephone and computer networks). These phenomena can be critical to understanding the existing technological system, forecasting how that system might evolve, and predicting the potential effect of some policy or event.

Incomplete Information Both innovation and diffusion of new technology are characterized by additional market failures related to incomplete information. While all investment is characterized by uncertainty, the uncertainty associated with the returns to investment in innovation is often particularly large. Also, information about the prospects for the success of a given technology research investment is asymmetric in the sense that the developer of the technology is in a better position to assess its potential than are outsiders. A firm attempting to raise investment capital to fund the development of new technology will therefore find such investors skeptical about promised returns and likely to demand a premium for investment that carries such risks. This likely imperfection in the market for capital for funding technology development exacerbates the spillover problem and therefore contributes to our expectation that the "invisible hand" encourages too little research and development.

With respect to technology adoption and diffusion, we have already discussed the fact that imperfect information can slow the diffusion of new technology. Incomplete information can also foster 
principal-agent problems, as when a builder or landlord chooses the level of investment in energy efficiency in a building, but the energy bills are paid by a later purchaser or a tenant. If the purchaser has incomplete information about the magnitude of the resulting energy savings, the builder or landlord may not be able to recover the cost of such investments and hence might not undertake them. These market failures with respect to adoption of new technology are part of the explanation for the apparent paradox of underinvestment in energysaving technologies that appear cost-effective but are not widely utilized (Jaffe and Stavins 1994).

Thus, the interplay of technology and the environment involves the interaction of two analytically distinct but linked sets of market failures. The consequences of this interaction can be complex. For example, the fact that markets underinvest in new technology strengthens the case for making sure that environmental policy is designed to foster rather than inhibit innovation. It may even mean that the social cost of environmental policy is less than would otherwise appear because part of the cost is in the form of investments in innovation that yield positive externalities outside the environmental arena. Whether this is true or not will depend on, among other things, whether the increased investment in environmental innovation brought forth by environmental policy comes at the expense of innovation in other areas. In practice, it may be difficult to sort out all these effects, and it may be very difficult to do so with quantitative reliability.

\section{Increasing Returns and Technology Lock-In}

Increasing returns to adopting a particular technology or system have been linked with so-called technology lock-in, in which a particular product, technical standard, production process, or service is produced by a market, and it is difficult to move to an alternative competing technology. Lock-in implies that, once led down a particular technological path, the barriers to switching may be prohibitive. For example, the evolution of the internal combustion engine and automobiles has included development of extensive infrastructure for the fueling and repair of these engines. If a superior technology based on a different fuel were developed, it would have to overcome the fact that gasoline can be purchased on every street corner, but other fuels are not widely available. In principle, this can lead to a "chicken and egg" problem, in which people won't buy the new technology because a related 
infrastructure doesn't exist, but firms do not want to invest in this infrastructure because there are no users.

Lock-in can be problematic if it would have been in the broader social interest to adopt a fundamentally different pattern of technological capacity. In turn, it raises the question of whether policy interventionspossibly involving central coordination and information assessment; direct technology subsidies; or publicly funded research, development, demonstration, and procurement programs-might avoid undesirable cases of technology lock-in by guiding technological paths in directions superior to those that would be taken by the free market. Nonetheless, an inefficient outcome need not necessarily result, and if it does, it may not be lasting. Market forces will eventually tend to challenge the predominance of an inferior technology (see Ruttan 1997).

While the empirical literature is quite sparse, some studies have explored the issue of increasing returns and technology lock-in for competing technologies within the energy and environment arenas, including analysis of the internal combustion engine and alternativefuel vehicles (Cowan and Hulten 1996), technologies for electricity generation (Islas 1997), nuclear power reactor designs (Cowan 1990), and the transition from hydrocarbon-based fuels (Kemp 1997). At a more aggregate level, there has been much discussion about whether it is possible for developing countries to take less environmentally damaging paths of development than were taken by currently industrialized countries, for example, by relying less on fossil fuels. ${ }^{3}$

We are far from having a well-established theoretical or empirical basis for deciding when intervention is preferable to an unregulated market outcome in the face of technology lock-in or the form that the intervention should take. Certainly, the observation that any nongasoline automobile technology faces a significant barrier in the form of lack of infrastructure is insufficient as a basis for concluding that other technologies are, in fact, socially superior. David (1997, p. 36) suggested that perhaps the most productive question to ask from the beginning is, How can we identify situations in which it is likely that at some future time individuals really would be better off had another equilibrium been selected? One thing that public policy can do, David suggested, is to try to delay the market from irreversible commitments before enough information has been obtained about the likely implications of an early, precedent-setting decision. ${ }^{4}$ One could construe current policy discussions surrounding certain biotechnology developments as potentially doing just that. 


\section{The Induced Innovation Approach}

The recognition that $R \& D$ is a profit-motivated investment activity leads to the hypothesis that the rate and direction of innovation are likely to respond to changes in relative prices. Because environmental policy implicitly or explicitly makes environmental inputs more expensive, the induced-innovation hypothesis suggests an important pathway for the interaction of environmental policy and technology, and for the introduction of impacts on technological change as a criterion for evaluation of different policy instruments. The induced-innovation hypothesis was first articulated by Sir John Hicks:

[A] change in the relative prices of the factors of production is itself a spur to invention, and to invention of a particular kind-directed to economizing the use of a factor which has become relatively expensive. (Hicks 1932, p. 124)

Hicks did not link the induced-innovation hypothesis in a formal way to the research process or to profit-maximizing R\&D decisions by firms, but others have. Binswanger and Ruttan (1978) summarize this literature. The general approach is to postulate a meta production function according to which investing in $\mathrm{R} \& \mathrm{D}$ changes the parameters of a production function. Unfortunately, theoretical conclusions regarding the induced effect of changes in factor prices on the parameters of the production function are sensitive to the specification of the meta production function governing the research process.

A natural way to move the modeling of induced innovation to the microeconomic level is to recognize that factor-saving technological change comes about mostly through the introduction of new capital goods that embody different input ratios. These input ratios can then be thought of as attributes or characteristics of the capital goods, as Lancaster (1971) did. Thirtle and Ruttan (1987) provided a review of the nonenvironmental literature on induced innovation. Much of this work is in the agricultural area, in which excellent microdata has long provided many opportunities for empirical work on innovation and diffusion. ${ }^{5}$ In general, available empirical analyses confirm that factor price changes are associated with factor-saving technological change.

One of the greatest challenges in testing the induced-innovation hypothesis specifically with respect to environmental inducement is the difficulty of measuring the extent or intensity of inducement across firms or industries (Jaffe et al. 1995). Ideally, one would like to look at the relationship between innovation and the perceived value to the 
firm of reducing pollution. In practice, this perceived value is not easily observed. Consequently, one must use proxies, such as characteristics of environmental regulations, expenditures on pollution abatement, or prices of polluting inputs (for example, energy). In the following paragraphs, we review studies that have used each of these approaches.

Many have written about the impact of environmental regulation on productivity and investment. ${ }^{6}$ To the extent that regulation inhibits investment and/or slows productivity growth, this can be viewed as indirect evidence suggesting that induced innovation effects on the rate of technological change are either small or are outweighed by other costs of regulation. Results on this issue seem to be industry and methodology dependent. For measuring the characteristics of environmental regulations, studies have used expert judgments about relative regulatory stringency in different states (Gray and Shadbegian 1998), number of enforcement actions (Gray and Shadbegian 1995), attainment status with respect to environmental laws and regulations (Greenstone 2002), and specific regulatory events (Berman and Bui 1998). ${ }^{7}$ Berman and Bui (1998) found significant productivity increases associated with air pollution regulation in the oil-refining industry, but Gray and Shadbegian (1998) found that pollution abatement investment crowds out productive investment almost entirely in the pulp and paper industry. Greenstone (2002) found that air pollution regulation has a statistically significant but very small impact on overall costs, implying a small negative productivity impact.

Lanjouw and Mody (1996) showed a strong association between pollution abatement expenditures and the rate of patenting in related technology fields. Jaffe and Palmer (1997) examined the correlation between pollution expenditures by industry and indicators of innovation more broadly. They found a significant correlation within industries over time between the rate of expenditure on pollution abatement and the level of R\&D spending. They did not, however, find evidence of an effect of pollution control expenditure on overall patenting.

Evidence of inducement has also been sought by examining the response to changing energy prices. Newell et al. (1999) examined the extent to which the energy efficiency of the menu of home appliances available for sale has changed in response to energy prices, using a model of induced innovation as changing characteristics of capital goods. In terms of the efficiency of the average model offered, they found that energy efficiency in 1993 would have been about 
one-quarter to one-half lower in air conditioners and gas water heaters if energy prices had stayed at their 1973 levels, rather than following their historical path. Most of the response to energy price changes came within less than five years of those changes.

Popp $(2001,2002)$ looked more broadly at energy prices and energyrelated innovation. Using energy-related patents as a proxy for energy innovation, he found that approximately one-third of the overall response of energy use to prices is associated with induced innovation, with the remaining two-thirds associated with factor substitution. Because energy patents are likely to measure energy innovation only with substantial error, one might interpret this result as placing a lower bound on the fraction of the overall response of energy use to changing prices that is associated with innovation.

In summary, there is considerable direct and indirect evidence that the rate and direction of technological change respond to economic incentives. On the time scale of decades, this response is quantitatively significant in the sense that improvements in efficiency associated with induced technological change are on the same order of magnitude as the improvements that appear to be occurring autonomously. This finding has important policy implications. First, it means that the longrun effectiveness of policies that increase the price of energy and other environmental inputs is likely to be greater than might be expected based on observed short-run responses. ${ }^{8}$ One can also turn this observation around and note that, for policy to have maximum impact, long periods of time will be required. Although empirical studies do not provide strong evidence on this point, the general observation that technology responds to incentives suggests that the relative effectiveness of different policy instruments in inducing innovation and technology diffusion may be an important consideration in policy choice.

\section{The Evolutionary Approach to Innovation}

It should be clear by now that the neoclassical economic analysis of these issues rests on-some might say, is mired in-the analytical concept of market failure. That concept rests, in turn, on the notion that in the absence of such failures, markets can be expected to produce socially efficient outcomes. A key tenet in this analysis of efficiency is an assumption that firms' decisions regarding innovation and adoption of new technology can be successfully analyzed through the lens of profit maximization. While viewing $R \& D$ as a profit-motivated 
investment activity comes naturally to most economists, the large uncertainties surrounding the outcomes of $R \& D$ investments make it very difficult for firms to make optimizing R\&D decisions. Accordingly, Nelson and Winter (1982) used Herbert Simon's idea of boundedly rational firms that engage in "satisficing" rather than optimizing behavior (Simon 1947) to build an alternative model of the R\&D process. In this evolutionary model, firms use "rules of thumb" and "routines" to determine how much to invest in R\&D and how to search for new technologies. The empirical predictions of this model depend on the nature of the rules of thumb that firms actually use (Nelson and Winter 1982, Winter et al. 2000).

Because firms are not optimizing, a logical consequence of the evolutionary model is that it cannot be presumed that the imposition of a new external constraint (for example, a new environmental rule) necessarily reduces profits. There is at least the theoretical possibility that the imposition of such a constraint could be an event that forces a satisficing firm to rethink its strategy, with the possible outcome being the discovery of a new way of operating that is actually more profitable for the firm. This possibility of environmental regulation leading to a win-win outcome in which pollution is reduced and profits are increased is discussed below.

The evolutionary approach replaces optimizing firms with satisficing firms and thereby admits greater scope for a variety of consequences when the firm's environment is modified. Satisficing firms may miss opportunities for increased profits simply because they do not look very hard for such opportunities as long as things are going reasonably well. An external shock such as a new environmental constraint can therefore constitute a stimulus to new search, possibly leading to discovery of previously undetected profit opportunities. This observation forms the basis for the normative observation that environmental regulation may not be as costly as we expect because the imposition of the new constraint may lead to the discovery of new ways of doing things. In the end, these new ways of doing things might actually be more profitable than the old ways, leading to an asserted win-win outcome:

It is sometimes argued that companies must, by the very notion of profit seeking, be pursuing all profitable innovation.... In this view, if complying with environmental regulation can be profitable, in the sense that a company can more than offset the cost of compliance, then why is such regulation necessary?

The possibility that regulation might act as a spur to [profitable] innovation arises because the world does not fit the Panglossian belief that firms always 
make optimal choices. ... [T] $]$ he actual process of dynamic competition is characterized by changing technological opportunities coupled with highly incomplete information, organizational inertia and control problems reflecting the difficulty of aligning individual, group and corporate incentives. Companies have numerous avenues for technological improvement, and limited attention. (Porter and van der Linde 1995, pp. 98-99)

Porter and other win-win theorists argue that in this nonoptimizing world, regulation may lead to "innovation offsets" that "not only lower the net cost of meeting environmental regulations, but can even lead to absolute advantages over firms in foreign countries not subject to similar regulations" (Porter and van der Linde 1995, p. 98). Of course, the fact that firms engage in nonoptimizing behavior creates a possibility for profit improvements, without suggesting that such improvements would be the norm, would be systematic, or would even be likely.

Quantitative evidence is limited. Porter and van der Linde (1995) provided numerous case studies of particular firms who developed or adopted new technology in response to regulation and appear to have benefited as a result. On the other hand, Palmer et al. (1995) surveyed firms affected by regulation-including those cited by Porter and van der Linde as success stories-and found that most firms say that the net cost to them of regulation is, in fact, positive. Boyd and McClelland (1999) and Boyd and Pang (2000) employ data envelopment analysis to evaluate the potential at paper and glass plants for improvements that both increase productivity and reduce energy use or pollution. They find that the paper industry could reduce inputs and pollution by 2 to 8 percent without reducing productivity. Other results discussed above suggest that the effect of environmental regulation on productivity is case-dependent and in many cases seems to be small.

\section{Summary of Analytical Issues}

The premise of this paper is that technological change is important for environmental policy and also that analysis of policy for energy and the environment benefits from the perspective of the economics of technological change. Our general approach is to view technological change relative to the environment as occurring at the nexus of two distinct and important market failures: pollution represents a negative externality, and new technology generates positive externalities. Hence, new technology for pollution reduction is, from an analytical perspective, 
doubly underprovided by markets. This suggests that the efficiency of environmental policy depends on its consequences for technological change and also that there is a potential role for policy aimed directly at the stimulation of environmentally beneficial technological change.

The subsequent sections look at these two policy approaches in more detail. Before doing so, it is perhaps useful to summarize what is known and unknown about the basic validity of the analytical perspective that we propose. At a fundamental level, a lot depends on one's view of the basic presumption that firms' behavior can be successfully modeled as acting rationally subject to the information constraints under which they operate. Rational firms will-eventually-respond to economic incentives, no matter how much information problems constrain their behavior. On the other hand, firms operating in a fog of uncertainty and asymmetric information may respond so slowly and poorly as to make models based on profit maximization unhelpful as a practical matter.

Viewed through this lens, the evidence on induced innovation and the win-win hypothesis is a case of a "partially full glass" that analysts see as mostly full or mostly empty, depending on their perspective. Apparently contradictory observations are, in effect, both true to a certain extent. Examples of this dialectic are provided in table 2.1 (in an intentionally provocative and perhaps imprecise manner).

\section{Effects of Environmental Policy on Technological Change ${ }^{9}$}

As noted above, if technological change responds to incentives, then it follows that different environmental policy instruments-which affect the incentives to develop and implement new technologies in different ways and to a varying extent-will have differing effects on the rate and direction of technological change. Many studies in environmental economics attempt to analyze these differences. While this literature is not entirely consistent in its conclusions, there is a general tendency that can be identified. Flexible policy instruments, based on economic incentives rather than mandatory compliance methods, are more likely to encourage the development and implementation of costeffective technology.

\section{Overview of the Issues}

For purposes of examining the link between environmental policy instruments and technological change, policies can be characterized as 
Table 2.1

Overview of conclusions on induced innovation and the win-win hyphothesis

Areas of agreement

Historical evidence indicates that a significant but not necessarily predominant fraction of innovation in the energy and environment area is induced.

Environmental regulation is likely to stimulate innovation and technology adoption that will facilitate environmental compliance.

Much existing environmental regulation uses inflexible mechanisms likely to stifle innovation; "incentive-based" mechanisms are likely to be more conducive to innovation.

Firms are boundedly rational so that external constraints may sometimes stimulate innovation that will leave the firm better off.

Areas of disagreement

\begin{tabular}{|c|c|}
\hline Win-win theory & Neoclassical economics \\
\hline $\begin{array}{l}\text { Widespread case-study evidence } \\
\text { indicates significant "innovation } \\
\text { offsets" are common. } \\
\text { Innovation in response to regula- } \\
\text { tion is evidence of offsets that } \\
\text { significantly reduce or eliminate } \\
\text { the cost of regulation. }\end{array}$ & $\begin{array}{l}\text { Case studies are highly selective. } \\
\text { Firms believe regulation is } \\
\text { costly. } \\
\text { When cost-reducing innovation } \\
\text { occurs, the opportunity cost of } \\
\text { R\&D and management effort } \\
\text { makes a true win-win outcome } \\
\text { unlikely. }\end{array}$ \\
\hline $\begin{array}{l}\text { Pollution is evidence of waste, } \\
\text { suggesting that cost-reducing } \\
\text { innovation in response to regula- } \\
\text { tion might be the norm. }\end{array}$ & $\begin{array}{l}\text { Costs are costs; even if firms are } \\
\text { not at the frontier, the side } \\
\text { effects of pollution reduction } \\
\text { could just as easily be bad as } \\
\text { good. }\end{array}$ \\
\hline $\begin{array}{l}\text { Existing productivity or cost } \\
\text { studies do not capture innova- } \\
\text { tion offsets. } \\
\text { There is much evidence of inno- } \\
\text { vation offsets, even though } \\
\text { existing regulations are badly } \\
\text { designed. This suggests that off- } \\
\text { sets from good regulation would } \\
\text { be large. }\end{array}$ & $\begin{array}{l}\text { Existing productivity and cost } \\
\text { studies suggest that innovation } \\
\text { offsets have been very small. } \\
\text { Since there is agreement that } \\
\text { bad regulations stifle innovation, } \\
\text { the apparent beneficial effects of } \\
\text { existing regulation show only } \\
\text { that case studies can be very } \\
\text { misleading. }\end{array}$ \\
\hline
\end{tabular}

either command-and-control or market-based approaches. Marketbased instruments-such as pollution charges, subsidies, tradeable permits, and some types of information programs-can encourage firms or individuals to undertake pollution-control efforts that are in their own interests and that collectively meet policy goals (Stavins 2003). Command-and-control regulations tend to force firms to take on similar shares of the pollution-control burden, regardless of the cost. They often do this by setting uniform standards for firms, the most 
prevalent of which are performance- and technology-based standards. But holding all firms to the same target can be expensive and, in some circumstances, counterproductive because standards typically exact relatively high costs by forcing some firms to resort to unduly expensive means of controlling pollution. Because the costs of controlling emissions may vary greatly among firms, and even among sources within the same firm, the appropriate technology in one situation may not be cost-effective in another.

All these forms of intervention have the potential for inducing or forcing some amount of technological change because, by their very nature, they induce or require firms to do things they would not otherwise do. While even technology-based standards may provide an incentive for innovation that reduces the cost of using specific technologies, performance standards allow a wider range of control options and innovation opportunities. Performance and technology standards can be explicitly designed to be "technology forcing," mandating performance levels that are not currently viewed as technologically feasible or mandating technologies that are not fully developed. One problem with these approaches, however, is that while regulators can typically assume that some amount of improvement over existing technology will always be feasible, it is impossible to know how much. Standards must be made unambitious, or else they run the risk of being ultimately unachievable, leading to political and economic disruption (Freeman and Haveman 1972).

Technology standards can be particularly problematic because they tend to freeze the development of technologies that might otherwise result in greater levels of control. Under regulations that are targeted at technologies, as opposed to emissions levels, no financial incentive exists for businesses to exceed control targets, and the adoption of new technologies is discouraged. Under a best available control technology (BACT) standard, a business that adopts a new method of pollution abatement may be "rewarded" by being held to a higher standard of performance and thereby not benefit financially from its investment, except to the extent that its competitors have even more difficulty reaching the new standard (Hahn and Stavins 1991). On the other hand, if third parties can invent and patent better equipment, they can-in theory - have a ready market. Under such conditions, a BACT type of standard can provide a positive incentive for technology innovation. Unfortunately, as we note below, there has been very little theoretical or empirical analysis of such technology-forcing regulations. 
In contrast with such command-and-control regulations, marketbased instruments can provide powerful incentives for companies to adopt cheaper and better pollution-control technologies because, with market-based instruments, it pays firms to clean up a bit more if a sufficiently low-cost technology or process for doing so can be identified and adopted.

\section{Technology Invention and Innovation}

Although decisions about technology invention and commercialization are partly a demand-side function of anticipated sales (adoption), the relevant literature comparing the effects of alternative environmental policy instruments has given greater attention to the supply side, focusing on incentives for firm-level decisions to incur R\&D costs in the face of uncertain outcomes. Early theoretical work (Magat 1978, 1979) compared taxes, subsidies, permits, effluent standards, and technology standards, and showed that all but technology standards would induce innovation biased toward emissions reduction. ${ }^{10}$

More recent theoretical work has found that the ranking of environmental policy instruments in terms of their ability to induce emissionsreducing innovation depends on circumstances (Fischer et al. 2003, Ulph 1997). This is partly due to the fact that any policy that controls emissions has two conflicting effects in terms of innovation incentives. On the one hand, by making pollution costly, it creates an incentive for emissions-reducing innovation. On the other hand, by increasing the overall cost of production, it tends to reduce the firms' output or sales, which reduces the incentive to perform R\&D. Katsoulacos and Xepapadeas (1996) found that a simultaneous tax on pollution emissions and subsidy for environmental R\&D may be better suited to overcoming the joint market failure (negative externality from pollution and positive externality or spillover effects of $R \& D$ ).

There has been exceptionally little empirical analysis directly of the effects of alternative policy instruments on technology innovation in pollution abatement, principally because of the paucity of available data. One study by Bellas (1998) carried out a statistical analysis of the costs of flue gas desulfurization (scrubbing) installed at coal-fired power plants in the United States under the new-source performance standards of the 1970 and 1977 Clean Air Acts, but it failed to find any evidence of the effects of scrubber vintage on cost, suggesting little technological innovation had taken place under this regulatory regime. 
Although there has been very little analysis in the context of pollution-abatement technologies, there is more extensive literature on the effects of alternative policy instruments on the innovation of energy-efficiency technologies because data have been available. As discussed above in the context of induced innovation more generally, there is evidence that increases in the price of energy have induced technological improvements in energy efficiency. There has also been some analysis of the effect of command-and-control regulations on energy efficiency. ${ }^{11}$ Of course, regulations designed to improve energy efficiency, such as appliance and automobile efficiency standards, have historically been implemented in response to rising energy prices, making it difficult to distinguish empirically the effect of these standards from the effect of rising energy prices. It is clear that minimum efficiency standards can increase the average efficiency of the menu of available equipment, if only by eliminating the least efficient models from the market (Newell et al. 1999). There is little doubt, for example, that the Corporate Average Fuel Economy (CAFE) standards for automobiles have made the automobile fleet more gasoline-efficient than it would otherwise have been. What is less clear is the extent to which such standards stimulate the development of new technology that makes possible improvements in the efficiency of the most efficient models, and whether comparable reductions in gasoline use could have been achieved at lower cost using incentive-based policy instruments.

\section{Technology Diffusion}

The predominant theoretical framework for analyses of diffusion effects has been what could be called the discrete technology choice model: firms contemplate the use of a certain technology that reduces marginal costs of pollution abatement and has a known fixed cost associated with it. While some authors have presented this approach as a model of innovation, it is more appropriately viewed as a model of adoption. With such models, several theoretical studies have found that the incentive for the adoption of new technologies is greater under market-based instruments than under direct regulation (Zerbe 1970, Downing and White 1986, Milliman and Prince 1989, Jung et al. 1996).

There is also empirical evidence regarding the effects of regulation on technology diffusion and on the superiority of incentive-based 
regulatory approaches in this regard. Two prominent examples of incentive-based environmental regulation in the United States are the phase-out of lead in gasoline in the 1980s and the reduction in sulfur dioxide emissions from power plants in the late 1990s, both of which were brought about using systems of tradeable permits. In both cases, empirical analysis shows that the incentives created by the permit system induced technology to (1) spread more rapidly, and (2) spread more efficiently in the sense that it increased incentives for firms to adopt compliance options that were cheaper for them (Kerr and Newell 2003, Keohane 2001).

The effect of energy price changes and regulations aimed at improving the energy efficiency of buildings, appliances, and industrial processes has been investigated by Jaffe and Stavins (1995), Hassett and Metcalf (1995), and Anderson and Newell (2003). In addition to the general finding that higher energy prices increase and adoption costs decrease the extent of adoption of energy-conservation technology (e.g., building insulation, more efficient home appliances, more efficient industrial motors), an interesting finding in this line of research is that the adoption of these technologies is more sensitive to the cost of the equipment than it is to the expected cost of energy. This finding implies that a policy of subsidizing the purchase of new efficient equipment may be more effective than a policy of taxing resource use, for policies that should in theory create the same magnitude of economic incentive. There are at least three possible explanations for this divergence. One possibility is a behavioral bias that causes purchasers to focus more on up-front cost than they do on the lifetime operating costs of an investment. An alternative view is that purchasers focus equally on both, but uncertainty about future energy prices or whether they will face these costs (e.g., because they could move) makes them give less weight to energy prices than they do to capital cost, which is known. A final interpretation might be that consumers have reasonably accurate expectations about future energy prices, and their decisions reflect those expectations, but the proxies for these expectations that are used by researchers are flawed, causing their measured effect to be smaller than their true effect. ${ }^{12}$

Although empirical evidence indicates that subsidies may be more effective than comparable taxes in encouraging technology diffusion, it is important to recognize some disadvantages of such subsidy approaches. First, unlike energy prices, adoption subsidies do not 
provide incentives to reduce utilization. Second, technology subsidies and tax credits can require large public expenditures per unit of effect because consumers who would have purchased the product even in the absence of the subsidy still receive it. In the presence of fiscal constraints on public spending, this raises questions about the feasibility of subsidies that would be sizable enough to have desired effects.

What about conventional command-and-control approaches? Jaffe and Stavins (1995) and Kemp (1997) examined the effects of more conventional regulations on technology diffusion in the form of building codes with energy-efficiency provisions. They found no discernible effects. It is unclear to what extent this is due to inability to measure the true variation across states in the effectiveness of codes or to codes that were in many cases not binding relative to typical practice. This is a reminder, however, that although price-based policies will always have some effect, typical command-and-control approaches may have little effect if they are set below existing standards of practice or below the level induced by price expectations.

Attention has also been given to the effects on energy-efficiency technology diffusion of voluntary environmental programs. Howarth et al. (2000) examined two voluntary programs of the U.S. Environmental Protection Agency: the Green Lights and Energy Star programs, both of which are intended to encourage greater private industry use of energy-saving technologies. A natural question from economics is, Why would firms carry out additional technology investments as part of a voluntary agreement? The authors respond that there are a set of agency problems that inhibit economically wise adoption of some technologies. For example, most energy-saving investments are small, and senior staff may rationally choose to restrict funds for small projects that cannot be perfectly monitored. The Green Lights program may be said to attempt to address this type of agency problem by providing information on savings opportunities at the level of the firm where decisions are made.

Another body of research has examined the effects on technology diffusion of command-and-control environmental standards when they are combined with "differential environmental regulations." In many situations where command-and-control standards have been used, the required level of pollution abatement has been set at a far more stringent level for new sources than for existing ones. There is empirical evidence that such differential environmental regulations 
have lengthened the time before plants were retired (Maloney and Brady 1988, Nelson et al. 1993). Also, this dual system can actually worsen pollution by encouraging firms to keep older, dirtier plants in operation (Stewart 1981, Gollop and Roberts 1983, McCubbins et al. 1989).

Although the empirical literature on the effects of policy instruments on technology diffusion by no means settles all the issues that emerge from the related theoretical studies, a consistent theme that runs through both the pollution-abatement and energy-efficiency empirical analyses is that market-based instruments are decidedly more effective than command-and-control instruments in encouraging the costeffective adoption and diffusion of relevant new technologies. This conclusion harks back to our summary at the end of Section II: while there is considerable dispute about the extent to which new technology reduces the social cost of environmental compliance, there is essentially no dispute that flexible, incentive-oriented policy approaches are the most likely to foster such lower-cost compliance paths.

\section{Environmental Technology Policy}

The previous section explored the potential for increasing the long-run cost-effectiveness of environmental policy by designing it explicitly to foster technological advance. Given that the development of environmentally beneficial technology is subject to two interacting market failures, however, it is likely that the rate of investment in such technology is below the socially optimal level, and it is unlikely that environmental policy alone creates the proper incentives. Hence, the optimal set of public policies likely also includes instruments designed explicitly to increase innovation and technology diffusion, as distinct from environmental policies that stimulate new technology as a side effect of internalizing the environmental externality.

Of course, one way to foster environmental technology is to foster technology in general and to assume that some portion of the stimulated development will be in the environment area. The arguments for generally greater public investment in technology infrastructure are well known and have been the subject of numerous papers in the Innovation Policy and the Economy series. Therefore, we will not attempt here to analyze the gamut of technology policy. We will focus instead on the potential for policies aimed explicitly at the development and diffusion of environmentally benign and/or energy-saving technology. 
There is a strong strain in U.S. technology policy of avoiding particular technical areas for support, that is, "picking winners." There are, however, two interrelated reasons why technology policy narrowly focused on energy and environment is likely to be socially desirable. First is the environmental externality itself, which makes environment, in effect, an area of government procurement like defense and space, and hence a suitable area for focused governmental technology efforts. Second, in the area of global climate change-arguably the most significant long-run environmental threat we face-the United States has largely put off, for the moment, environmental policy intervention. Hence, there is little environmental policy-induced incentive to develop technologies that reduce greenhouse-gas emissions. This stance says, in effect, that this is a potentially serious problem, but it is so far off and the uncertainties are so large that we will limit policy intervention to research and development for the moment. Hence, policy to foster greenhouse-gas-reducing technology is the main policy lever available.

\section{Policies Aimed at Stimulating Innovation}

Policies that internalize the cost of environmental harm stimulate the creation of environment-friendly technology by increasing the demand for low-cost pollution-reduction methods. This increases the return to developing such technologies. The spillover problem implies that firms can expect to capture only a portion of that return, but a portion of a large return is still more of an incentive than a portion of a small return. Government can also stimulate innovation through the supply side, either by making it less expensive for firms to undertake research in this area or by performing such research in public institutions.

When research produces potentially large social benefits but is so prone to the spillover problem that firms will not view it as profitable, there is an analytical basis for performing that research in the public sector or through direct private research contracts. There is a long tradition of performing such basic research at the U.S. National Energy Laboratories. The national labs, such as Lawrence Berkeley, Brookhaven, Oak Ridge, Sandia, Lawrence Livermore, and the National Energy Technology Lab are typically owned by the U.S. Department of Energy but operated by either a private firm or a university. Most of the research on energy and environment that is performed at these facilities is funded by the Department of Energy and other federal agencies. 
As noted above, an additional reason for directed public funding on specific energy-environment topics is that, at the moment, the demandside incentive to develop greenhouse-gas-reducing technologies is limited because there are inadequate policies for internalizing the climate change externality.

As long as firms see some potential for private return, public policy can counterbalance the spillover problem by subsidizing research in the private sector rather than performing it in the public sector. The advantage of this approach is that private firms may have better information than the government about the likely commercial feasibility of different technologies and hence be more successful at choosing which technologies to pursue. Such subsidies can take the form of fairly general tax credits, or matching funds that are provided to firms for specific research proposals. In areas where the national labs have specific expertise, joint industry-government research can be undertaken using the mechanism of the Cooperative Research and Development Agreement (CRADA). Finally, because the supply of appropriately trained scientists and engineers is relatively inelastic in the short run, there is a danger that any increased expenditure on research in a given area will be at least partly consumed by an increase in wages (Goolsbee 1998), rather than going to more research effort. This tendency can be offset if subsidies to or expenditures on research are complemented by subsidies for education and training in the appropriate areas. ${ }^{13}$

\section{Policies Aimed at Stimulating Adoption}

There is a long history of public support for research in the United States. There has been less policy consensus regarding the desirability of using public policy to speed the adoption of new technology. Because of the positive information externality associated with technology adoption, there is a valid analytical basis for considering such policy. Also, if learning curves or other sources of dynamic increasing returns are important, there could be large social benefits associated with speeding diffusion of new energy-saving or otherwise environmentally beneficial technologies. On the other hand, the possibility of technology lock-in makes this a potentially two-edged sword. If the government encourages the diffusion of a particular technology, it is possible that it could become so entrenched in the marketplace that it stifles the development of some other, superior technology. This danger creates a tension in the design of policies to encourage adoption. 
To maximize the exploitation of dynamic increasing returns, it is desirable to focus on the development of a small number of promising technologies. Yet to avoid accidentally helping to entrench the wrong technology, it is desirable for policy to be "technology neutral," that is, encouraging all efforts that achieve specified objectives without focusing on a particular approach.

Thus, a potential trade-off exists between technology portfolio diversification and increasing returns from a focus on a small number of technologies. In addition, given limited public resources, the government clearly cannot subsidize all new technologies, so there is a need to focus scarce resources on commercialization opportunities for which there is the clearest need for a public role. As stated earlier, this case will be more compelling the lower are the private incentives for adoption, as in the case of environmental problems that have not otherwise been fully priced into private decisions.

As with research, the government can encourage adoption both in its own operations and by subsidizing the efforts of others. Because the government is a very large landlord, vehicle operator, and user of many other kinds of equipment, its decision to purchase certain technologies for its own use could have a significant effect on the rate of diffusion of that technology. Technology diffusion, and achievement of any associated benefits of dynamic increasing returns, can also be encouraged with tax credits that reduce the effective purchase price of new equipment that meets specified criteria.

Because a major aspect of the market failure in technology diffusion is imperfect information, another category of policy to encourage diffusion is information provision. With respect to technologies that appear cost-effective but are not yet widely utilized, this kind of policy overcomes the apparent market failure without putting the government in the position of betting on particular technologies.

Finally, command-and-control regulations can also be used to try to force the diffusion of particular technologies, if only by removing less expensive and less environmentally beneficial competing technologies from the market. The Corporate Average Fuel Economy (CAFE) standards have been designed to force an improvement in auto efficiency. Energy efficiency standards have also been implemented for major home appliances. In principle, such standards can be beneficial by conserving the need for every individual to undertake the information and assessment process inherent in trading off capital and energy operating costs. However, they also raise the risk of going beyond an economically justified minimum, at which point they can impose limits to 
Table 2.2

Overview of U.S. federal climate technology R\&D and adoption initiatives

Climate-related technology R\&D spending ( $\$ 1.1$ billion/year)

Energy conservation

$53 \%$

Renewables supply

Carbon capture and sequestration

$37 \%$

Basic science

$5 \%$

EPA science and technology

$3 \%$

Forest, range, agriculture

$2 \%$

Energy Information Administration

$1 \%$

$<1 \%$

Climate-related technology adoption spending ( $\$ 1$ billion/year)

State energy efficiency grants $33 \%$

Renewables production tax incentives

Cogeneration production tax incentives

$22 \%$

EPA information/voluntary programs

Hybrid/fuel cell car tax credits

product choice and undesirable costs on what is a very heterogeneous population of adopters.

\section{Current Climate Policy Efforts}

As an illustration of the range of federal technology policy initiatives related to energy and environment, table 2.2 summarizes current federal climate change initiatives. Based on the fiscal year 2003 (FY03) budget request (Connaughton 2002), about $\$ 1$ billion will be spent on research, and a similar amount will be spent on technology diffusion. On the research side, a little over half relates to energy conservation, with most of the remainder going toward sources of renewable energy. On the diffusion side, a little over half goes toward tax credits for renewable energy production, cogeneration, hybrid/fuel cell autos, landfill gas production, and solar homes. About one-third of the money goes for state energy efficiency grants, and 9 percent for EPA information and voluntary programs such as Green Lights.

\section{Assessment}

Generally, with science and technology programs, systematic assessment efforts are woefully lacking. Because success is uncertain and difficult to measure, most agencies engaged in the support of research 
and technology adoption have resisted efforts to measure their output against quantitative benchmarks, as is required by the Government Performance and Results Act (Jaffe 1998, 2002). Granted, such evaluation is very difficult, and there is a real danger that imperfect assessment methods will distort policy by encouraging efforts that "look good" on the evaluation, even if such efforts are not ideally suited to the program's mission. But continuous, systematic, quantitative assessment is the only way that the relative effectiveness of different policy approaches can be compared over time. In particular, collecting data in a standardized way as projects are begun, implemented, and terminated is the only way to amass the data necessary for a rigorous retrospective analysis.

The analyses that have been conducted of federal research related to energy and the environment have reached mixed conclusions. Cohen and Noll (1991) documented the monumental waste represented by the breeder reactor and synthetic fuel programs in the 1970s, but also concluded that the photovoltaics research program undertaken in the same time frame had significant benefits. More recently, the National Research Council attempted a fairly comprehensive overview of energy efficiency and fossil energy research at DOE over the last two decades (National Research Council 2001). Using both estimates of overall return and case studies, they concluded, as one might expect, that there were only a handful of programs that proved highly valuable. Their estimates of returns suggest, however, that the benefits of these successes amply justified the overall portfolio investment.

Perhaps more important than the question of the overall rate of return is what distinguishes the successful programs from the failures. While the small numbers and inherent randomness make it difficult to draw strong conclusions, it seems that the successful programs are those in which significant participation by industry -in the form of many firms or consortia rather than individual contractors-helped to ensure that the photovoltaics, building energy efficiency, and advanced engine programs produced outputs that are actually or potentially of real commercial value.

There is also some evidence of success for information programs (Anderson and Newell 2003). The Department of Energy provides free energy audits to small and medium-size companies using universitybased engineering teams recommending energy-saving projects that appear to be desirable. DOE has maintained an extensive database on 
the technology costs, projected energy savings, and adopted recommendations. Overall, about 50 percent of recommended projects are adopted. These programs are relatively inexpensive and so are probably earning a reasonable social return. But firms' decisions to adopt only 50 percent of the projects recommended by the engineering experts suggest that imperfect information is not the only reason for nonadoption.

\section{Conclusions}

Economists generally evaluate public policies that intervene in the market economy from the analytical perspective of market failure. When it comes to green technology, two mutually reinforcing sets of market failures are at work, which makes it very likely that the rate of investment in the development and diffusion of such technology is less than would be socially optimal. There are two generic sets of approaches to this situation. One is to design environmental policy so that it fosters the development and diffusion of new technology, by increasing the perceived market payoff and maximizing flexibility in compliance. The other is to implement policies aimed directly at the development and diffusion of environmentally friendly technologies.

Theory suggests and empirical research confirms that innovation and technology diffusion do respond to the incentives of the market and that properly designed regulation can create such incentives. Some believe that technology is so responsive to regulatory incentives that the social cost of environmental regulation is very low, or even negative, implying that regulation stimulates so much new technology that society is better off even without consideration of the environment. Much paper has been consumed (or recycled?) debating this win-win hypothesis. But there is no significant disagreement that environmental policy based on incentives rather than command-and-control approaches maximizes the potential to stimulate cost-effective technology innovation and diffusion. Yet many existing environmental regulations retain significant command and control features. Reform of such policies and flexible design of prospective policies would be socially beneficial. To a significant extent, it does not matter whether the end point of such reform would be truly win-win or merely achieving the same environmental objectives at lower (but possibly still substantial) cost.

The double-market failure also suggests that there is a clear case for broad-based public support of technology innovation and diffusion. 
And in cases where private incentives do not reflect the full costs of environmental externalities, for whatever reason, the optimal policy mix will include public policies aimed directly at stimulating the development and diffusion of new environmentally benign technology. This argument is particularly strong with respect to those aspects of technology development that are most influenced by market failure in the form of difficulty by private firms in appropriating the returns to innovation and adoption. Technology "infrastructure," such as data collection and dissemination and the training of scientists and engineers, is likely to be seriously underprovided by market incentives.

Technology policy that goes beyond basic scientific research and leans toward the development and diffusion of specific technologies is politically controversial. There are good reasons for this controversy, including doubts that the government is efficient at deciding what aspects of technology to support, and painful experience with illadvised initiatives that became difficult to end once political momentum developed behind them. But problems such as global climate change are too important, and the positive externalities associated with development and adoption of new technology in this area are too clear to abandon policy efforts simply because they are hard. Everyone agrees that there are many ways in which public education is flawed, but it is not widely suggested that, as a consequence, the government should simply get out of the business of education. Rather, we should try different ways to structure policy in this area to minimize the known policy problems, such as public-private partnerships that subsidize research but retain a significant element of market forces in determining which technologies to pursue. Failure of some policy initiatives should be expected, and such failure should be used to terminate or improve particular programs, not to rationalize total inaction.

A logical counterpart of policy experimentation is systematic policy evaluation. Unfortunately, it is very difficult to measure policy success when the output is intangible and its effects are manifest in the economy only over long periods. Indeed, some advocates of public investment in technology resist quantitative evaluation of technology programs on the grounds that it is so hard to measure the outputs that any attempted measurements will necessarily understate the benefits and hence undermine political support for such programs. But acceptance of this approach guarantees perpetuation of our ignorance about how to solve the problems inherent in public involvement in this area, 
and thereby consigns technology policy forever to the realm of ideology. Technological change is a long-run process, and we should be willing to take a long-run view, and we should remain hopeful that, on the time scale of years and decades, systematic evaluation will eventually allow the creation of a solid empirical base for the design of technology policy to maximize its social returns.

\section{Notes}

1. Josef Schumpeter identified three steps in technological change: invention, innovation, and diffusion. In Schumpeter's trichotomy, invention is the first technical development, and innovation the first commercial introduction. For simplicity, we have collapsed these two steps into one and labeled it innovation.

2. There is, however, an offsetting negative externality because R\&D is a fixed cost that must, in equilibrium, be financed by the stream of quasi-rents it produces. The entry of another R\&D competitor, or an increase in the R\&D investment level of a competitor, reduces the expected quasi-rents earned by other R\&D firms. This "rent-stealing" effect (Mankiw and Whinston 1986) could, as a theoretical matter, lead to overinvestment in R\&D. The empirical evidence suggests, however, that positive externalities associated with knowledge spillovers dominate the rent-stealing effect, leading to social rates of return for $R \& D$ substantially in excess of the private rates of return (Griliches 1992).

3. See the survey by Evenson and Westphal (1995) on technology and development.

4. See Majd and Pindyck (1989) for an analysis that explicitly treats learning by doing as an irreversible investment decision.

5. More recently, the availability of computerized firm-level data on production costs, R\&D, and patents has led to an increase in parallel analyses in the industrial sector.

6. See, for example, Gollop and Roberts (1983), Kolstad and Turnovsky (1998), and Yaisawarng and Klein (1994).

7. Of course, there is a parallel problem with respect to measurement of the rate of invention or innovation. See Griliches (1990) and Lanjouw and Schankerman (1999).

8. Of course, one expects long-run responses in general to exceed short-run responses. But in the absence of induced technological change, diminishing marginal returns would likely limit the extent of possible substitution effects, even in the long run.

9. For a detailed survey of the issues in this section, see Jaffe, Newell, and Stavins (2002).

10. A considerable amount of theoretical work followed in the 1980s. Although much of that work characterized its topic as the effects of alternative policy instruments on technology innovation, the focus was in fact on effects of policy on technology diffusion. Hence, we defer consideration of those studies to the next section.

11. See, for example, Greening et al. (1997) and Newell et al. (1999) on appliance efficiency standards, and Goldberg (1998) and Greene (1990) on the Corporate Average Fuel Economy (CAFE) standards for automobiles. 
12. For example, studies often use current, realized energy prices as a proxy for expected, future energy prices. Current prices fluctuate more than expected future prices, however, leading to a downward bias in the coefficient on the energy price proxy relative to the true relationship with expected prices.

13. For a general discussion of support for training and education as a complement to research subsidies, see Romer (2000).

\section{References}

Anderson, S. T. and R. G. Newell. 2003. Information Programs for Technology Adoption: The Case of Energy-Efficiency Audits. Resource and Energy Economics, forthcoming.

Bellas, A. S. 1998. "Empirical Evidence of Advances in Scrubber Technology." Resource and Energy Economics 20: 327-43.

Berman, E., and L. Bui. 1998. "Environmental Regulation and Labor Demand: Evidence from the South Coast Air Basin." Working Paper No. 6776. Cambridge, MA: National Bureau of Economic Research.

Binswanger, H. P., and V. W. Ruttan. 1978. Induced Innovation: Technology, Institutions, and Development. Baltimore, MD: Johns Hopkins University Press.

Boyd, G., and J. McClelland. 1999. "The Impact of Environmental Constraints on Productivity Improvement and Energy Efficiency an Integrated Paper and Steel Plants." The Journal of Economics and Environmental Management 38: 121-46.

Boyd, G., and J. Pang. 2000. "Estimating the Linkage Between Energy Efficiency and Productivity." Energy Policy 28: 289-96.

Cohen, Linda R., and R. G. Noll. 1991. The Technology Pork Barrel. Washington, DC: Brookings.

Connaughton, James L. 2002. Statement on United States Global Climate Change Strategy for the Joint Hearing Before the Committee On Environment and Public Works and the Committee on Foreign Relations. Washington, DC: United States Senate.

Cowan, R. 1990. "Nuclear Power Reactors: A Study in Technological Lock-In." Journal of Economic History 50: 541-67.

Cowan, R., and S. Hulten. 1996. "Escaping Lock-In: The Case of the Electric Vehicle." Technological Forecasting and Social Change 53: 61-79.

David, P. A. 1997. "Path Dependence and the Quest for Historical Economics: One More Chorus in the Ballad of QWERTY." Discussion Papers in Economic and Social History, Number 20, University of Oxford.

Downing, P. B., and L. J. White. 1986. "Innovation in Pollution Control." Journal of Environmental Economics and Management 13: 18-29.

Energy Modeling Forum. 1996. Markets for Energy Efficiency, EMF Report 13, Volume I, Stanford University.

Evenson, R., and L. E. Westphal. 1995. "Technology Change and Technology Strategy." In J. Behrman and T. N. Srinivasan, eds., Handbook of Development Economics, Vol. 3A. Amsterdam: North-Holland, 2209-2299. 
Fischer, C., I. W. H. Parry, and W. A. Pizer. 2003. "Instrument Choice for Environmental Protection When Technological Innovation Is Endogenous." Journal of Environmental Economics and Management, 45(3): 523-45.

Freeman, A. M., and R. H. Haveman. 1972. "Clean Rhetoric and Dirty Water." Public Interest 28: 51-65.

Goldberg, P. K. 1998. "The Effects of the Corporate Average Fuel Efficiency Standards in the U.S." Journal of Industrial Economics 46: 1-3.

Gollop, F. M., and M. J. Roberts. 1983. "Environmental Regulations and Productivity Growth: The Case of Fossil-Fueled Electric Power Generation." Journal of Political Economy 91: 654-74.

Goolsbee, A. 1998. "Does Government R\&D Policy Mainly Benefit Scientists and Engineers?" American Economic Review 88: 298-302.

Gray, W. B, and R. J. Shadbegian. 1995. "Pollution Abatement Costs, Regulation, and Plant-Level Productivity." Working Paper No. 4994. Cambridge, MA: National Bureau of Economic Research.

Gray, W. B., and R. J. Shadbegian. 1998. "Environmental Regulation, Investment Timing, and Technology Choice." Journal of Industrial Economics 46: 235-56.

Greene, David L. 1990. "CAFE or Price? An Analysis of the Effects of Federal Fuel Economy Regulations and Gasoline Price on New Car MPG, 1978-89." The Energy Journal 11(3): $37-57$.

Greening, Lorna A., Alan H. Sanstad, and James E. McMahon. 1997. "Effects of Appliance Standards on Product Price and Attributes: An Hedonic Pricing Model." Journal of Regulatory Economics 11: 181-94.

Greenstone, M. 2002. "The Impacts of Environmental Regulations on Industrial Activity: Evidence from the 1970 and 1977 Clean Air Act Amendments and the Census of Manufactures." Journal of Political Economy 110(6): 1175-1219.

Griliches, Z. 1990. "Patent Statistics as Economic Indicators: A Survey." Journal of Economic Literature 28: 1661-1707.

Griliches, Z. 1992. "The Search for R\&D Spillovers." Scandinavian Journal of Economics 94: S29-S47.

Hahn, R. W., and R. N. Stavins. 1991. "Incentive-Based Environmental Regulation: A New Era from an Old Idea?" Ecology Law Quarterly 18: 1-42.

Hassett, K. A., and G. E. Metcalf. 1995. "Energy Tax Credits and Residential Conservation Investment: Evidence form Panel Data." Journal of Public Economics 57: 201-217.

Hicks, J. 1932. The Theory of Wages. London: Macmillan.

Howarth, R. B., B. M. Haddad, and B. Paton. 2000. "The Economics of Energy Efficiency: Insights from Voluntary Participation Programs." Energy Policy 28: 477-86.

Islas, J. 1997. "Getting Round the Lock-In in Electricity Generating Systems: The Example of the Gas Turbine." Research Policy 26: 49-66.

Jaffe, Adam B. 1998. "Measurement Issues." In L. M. Branscomb and J. Keller, eds., Investing in Innovation. Cambridge, MA: MIT Press: 64-84. 
Jaffe, Adam B. 2002. "Building Programme Evaluation into the Design of Public Research-Support Programmes." Oxford Review of Economic Policy 18: 22-34.

Jaffe, A. B., R. G. Newell, and R. N. Stavins. 2002. "Environmental Policy and Technological Change." Environmental and Resource Economics 22(1-2): 41-69.

Jaffe, A. B., and K. Palmer. 1997. "Environmental Regulation and Innovation: A Panel Data Study." Review of Economics and Statistics 79: 610-19.

Jaffe, A. B., S. Peterson, P. Portney, and R. N. Stavins. 1995. "Environmental Regulation and the Competitiveness of U.S. Manufacturing: What Does the Evidence Tell Us?" Journal of Economic Literature 33: 132-63.

Jaffe, A. B., and R. N. Stavins. 1994. "The Energy Paradox and the Diffusion of Conservation Technology." Resource and Energy Economics 16: 91-122.

Jaffe, A. B., and R. N. Stavins. 1995. "Dynamic Incentives of Environmental Regulations: The Effects of Alternative Policy Instruments on Technology Diffusion." Journal of Environmental Economics and Management 29: 43-63.

Jung, C. H., K. Krutilla, and R. Boyd. 1996. "Incentives for Advanced Pollution Abatement Technology at the Industry Level: An Evaluation of Policy Alternatives." Journal of Environmental Economics and Management 30: 95-111.

Katsoulacos, Y., and A. Xepapadeas. 1996. "Environmental Innovation, Spillovers and Optimal Policy Rules." In C. Carraro et al., eds., Environmental Policy and Market Structure. Dordrecht: Kluwer Academic Publishers: 143-50.

Kemp, R. 1997. Environmental Policy and Technical Change. Cheltenham, UK: Edward Elgar.

Keohane, N. O. 2001. "Essays in the Economics of Environmental Policy." Unpublished Ph.D. Dissertation, Harvard University.

Kerr, S., and R. G. Newell. 2003. "Policy-Induced Technology Adoption: Evidence from the U.S. Lead Phasedown." Journal of Industrial Economics, forthcoming.

Kolstad, C. D., and M. H. L. Turnovsky. 1998. "Cost Functions and Nonlinear Prices: Estimating a Technology with Quality-Differentiated Inputs." Review of Economics and Statistics 80: 444-53.

Lancaster, K. 1971. Consumer Demand: A New Approach. New York: Columbia University Press.

Landjouw, J. O., and A. Mody. 1996. "Innovation and the International Diffusion of Environmentally Responsive Technology." Research Policy 25: 549-71.

Lanjouw, J., and M. Schankerman. 1999. "The Quality of Ideas: Measuring Innovation with Multiple Indicators." Working Paper No. 7345. Cambridge, MA: National Bureau of Economic Research.

Magat, W. A. 1978. "Pollution Control and Technological Advance: A Dynamic Model of the Firm." Journal of Environmental Economics and Management 5: 1-25.

Magat, W. A. 1979. "The Effects of Environmental Regulation on Innovation." Law and Contemporary Problems 43: 3-25.

Majd, S., and R. S. Pindyck. 1989. "The Learning Curve and Optimal Production Under Uncertainty." Rand Journal of Economics 20: 331-43. 
Maloney, M. T., and G. L. Brady. 1988. "Capital Turnover and Marketable Pollution Rights." Journal of Law and Economics 31: 203-226.

Mankiw, N. G., and M. D. Whinston. 1986. "Free Entry and Social Inefficiency." Rand Journal of Economics 17: 48-58.

McCubbins, M. D., R. G. Noll, and B. R. Weingast. 1989. "Structure and Process, Politics and Policy: Administrative Arrangements and the Political Control of Agencies." Virginia Law Review 75: 431-82.

Milliman, S. R., and R. Prince. 1989. "Firm Incentives to Promote Technological Change in Pollution Control." Journal of Environmental Economics and Management 17: 247-65.

National Research Council. 2001. Energy Research at DOE: Was It Worth It? Washington, DC: National Academy Press.

Nelson, R., T. Tietenberg, and M. Donihue. 1993. "Differential Environmental Regulation: Effects on Electric Utility Capital Turnover and Emissions." Review of Economics and Statistics 75: 368-73.

Nelson, R., and S. Winter. 1982. An Evolutionary Theory of Economic Change. Cambridge, MA: The Belknap Press of Harvard University Press.

Newell, R. G, A. B. Jaffe, and R. N. Stavins. 1999. "The Induced Innovation Hypothesis and Energy-Saving Technological Change." The Quarterly Journal of Economics 114: 941-75.

Palmer, K., W. E. Oates, and P. R. Portney. 1995. "Tightening Environmental Standards: The Benefit-Cost or the No-Cost Paradigm?" Joumal of Economic Perspectives 9: 119-32.

Popp, D. 2001. "The Effect of New Technology on Energy Consumption." Resource and Energy Economics 23(4): 215-39.

Popp, D. 2002. "Induced Innovation and Energy Prices." American Economic Review, 92(1): 339-49.

Porter, M. E., and C. van der Linde. 1995. "Toward a New Conception of the Environment-Competitiveness Relationship." Journal of Economic Perspectives 9: 97-118.

Romer, P. 2001. "Should the Government Subsidize Supply or Demand in the Market for Scientists and Engineers?" In A. Jaffe et al., eds., Innovation Policy and the Economy, Volume 1. Cambridge, MA: MTT Press: 221-52.

Ruttan, V. W. 1997. "Induced Innovation, Evolutionary Theory and Path Dependence: Sources of Technical Change." Economic Journal 107: 1520-29.

Simon, H. A. 1947. Administrative Behavior: A Study of Decision-Making Processes in Administrative Organization. New York: Macmillan Company.

Stavins, R. N. 2003. "Experience with Market-Based Environmental Policy Instruments." In Karl-Göran Mäler and Jeffrey Vincent, eds., Handbook of Environmental Economics, Volume I. Amsterdam: Elsevier Science: Chapter 9, 355-435.

Stewart, R. B. 1981. "Regulation, Innovation, and Administrative Law: A Conceptual Framework." California Law Review 69: 1256-70.

Thirtle, C. G., and V. W. Ruttan. 1987. "The Role of Demand and Supply in the Generation and Diffusion of Technical Change." Fundamentals of Pure and Applied Economics, vol. 21. New York: Harwood Academic Publishers. 
Ulph, D. 1997. "Environmental Policy and Technological Innovation." In C. Carraro and D. Siniscalaco, eds., New Directions in the Economic Theory of the Environment. Cambridge: Cambridge University Press: 43-68.

Weyant, J. P. 1993. "Costs of Reducing Global Carbon Emissions." Journal of Economic Perspectives 7: 27-46.

Winter, S. G., Y. M. Kaniovski, and G. Dosi. 2000. "Modeling Industrial Dynamics with Innovative Entrants." Structural Change and Economic Dynamics 11: 255-93.

Yaisawarng, S., and J. D. Klein. 1994. "The Effects of Sulfur Dioxide Controls on Productivity Change in the U.S. Electric Power Industry." Review of Economics and Statistics 76: 447-60.

Zerbe, R. O. 1970. "Theoretical Efficiency in Pollution Control." Western Economic Journal 8: $364-76$. 